\title{
SECRETION OF ECCRINE SWEAT GLANDS DURING EXERCISE
}

\author{
P. PILARDEAU, ${ }^{1}$ J. VAYSSE, ${ }^{2}$ M. GARNIER, ${ }^{3}$ M. JOUBLIN, ${ }^{4}$ L. VALERI, ${ }^{5}$ \\ ${ }^{1}$ Cons. Physician, Hôp. de BONDY, Av. du 14 juil. 93 140, PARIS \\ ${ }^{2}$ Hôpital de BONDY, ${ }^{3}$ Dept. of Biochemistry, Hop. de BONDY \\ 'Cons. in Rehabilitation, I'hopital de MEAUX 77 \\ ${ }^{5}$ Cons. Anaesthetist, Hôpital Franco-Musulman 93 000, S.A.M.U. 93, PARIS
}

\section{INTRODUCTION}

The mechanisms of sweat secretion during work are of great importance, so the present study was undertaken to investigate the mechanisms of metabolite excretion during training.

These considerations have generated a great deal of interest in the function of the sweat glands, but the practical difficulties involved in the collection and analysis of samples of human sweat have retarded investigations of the mechanisms of fluid and electrolyte secretion by this tissue.

We have attempted to find a relationship between the level of sweat secretion and the training of athletes under aerobic and anaerobic conditions.

Besides the immediate response of sweat secretion due to myoepithelial cells during work, we can envisage a common mechanism between the energy contribution of muscle fibres and eccrine sweat cells.

\section{SUBJECTS AND METHODS}

\section{Methods of Sampling}

After a $15 \mathrm{~min}$. warm-up (to eliminate presecreted sweat) the sweat is collected with filter paper (covered with a piece of cellophane) and weighed before and after application.

The forehead is first thoroughly washed with distilled water, then the paper is removed after $30 \mathrm{~min}$. of play and weighed again. The volume of sweat is calculated by the weight difference.

\section{Athletes}

The study relates to three groups of athletes:

Football players $(\mathrm{N}=12)$ working in relative anaerobic conditions (one sample taken from each player).

Walkers $(N=12)$ trained and working under aerobic conditions (three samples taken during the competition).

\footnotetext{
These studies were carried out under the auspices of I'INSTITUT UNIVERSITAIRE "SPORT ET SANTE" (Président P. CORNILLOT), Faculté de biologie et de medecine, 74 rue Marcel Cachin, BOBIGNY 93000.
}

Two table tennis players, untrained (twenty samples) working in relative anaerobic conditions.

\section{Procedure for sampling}

The room temperature was constant during work.

$18^{\circ} \mathrm{C}$ for football players and table tennis players.

$10^{\circ} \mathrm{C}$ for walkers.

For walkers we collected urine and sweat samples before, during and after training.

Each sample was collected in a different bottle.

\section{Methods of Assay}

The sweat collected on the paper is eluated with $10 \mathrm{ml}$. of distilled water. Urines are assayed directly.

$\mathrm{Na}^{+}$and $\mathrm{K}^{+}$. Sodium and potassium are assayed using a photometric method. Results expressed in $\mathrm{mEq} /$ /itre of sweat.

Glucose. The glucose in sweat is determined by Hultman's technique (Orthotoluidine). Results expressed in $\mathrm{g} / \mathrm{l}$ of sweat.

Lactate. The lactate is determined by enzymatic method (Gutmann and Walhefeld). The decrease in the NADH concentration is directly proportional to the lactate concentration. Results into $\mathrm{g} / \mathrm{l}$ of sweat.

Pyruvate. It is usually titrated by an enzymatic method (Szohr and Lamprecht). Results expressed in $\mathrm{mg} / \mathrm{l}$.

Chloride. The chloride is determined by complexometric technique (Schales and Schales). Results expressed in $\mathrm{mEq} / \mathrm{l}$ of sweat.

\section{RESULTS}

These are best displayed in the form of graphs and histograms.

\section{DISCUSSION}

Eccrine glands are controlled by two systems, neural control and endocrine control. Eccrine sweating is under 
neural cholinergic control and the myoepitelial cells are adrenergic. (Adelman et al, 1975; Robertshaw, 1977 and Uno and Montagna, 1975).

The sensibility of eccrine gland to catecholamines suggests, however, that circulating catecholamines play a physiological role. (Allen and Roddie, 1972). Circulating catecholamines of adrenomedullary origin could have been the hormonal factors that stimulated sweating during exercise. (Das et al, 1975; Foster et al, 1970 and Robertshaw, 1975).

The studies of Collins (1962); Collins and Weiner (1970) and Sato and Dobson (1970) showed the effect of aldosterone on the sodium concentration of sweat. Aldosterone raised the level of potassium in sweat secretion by exchange with sodium. (Cage and Dobson, 1965).

Our method shows that the lactate secretion is higher for anaerobic exercise, and we find significantly different regression lines for aerobic and anaerobic exercise. The lactic acid excreted by human sweat glands has no bearing on the blood level of lactic acid. In this study, we want to show that a relation exists between the metabolic state of muscle fibres and eccrine cells. $(\mathrm{pH}$, $\mathrm{O}_{2}$ energetic). If this relation can be established, it is possible to create simple tests to estimate the peripheral "atmosphere" of these tissues during work. These tests are non invasive and easily reproducible.

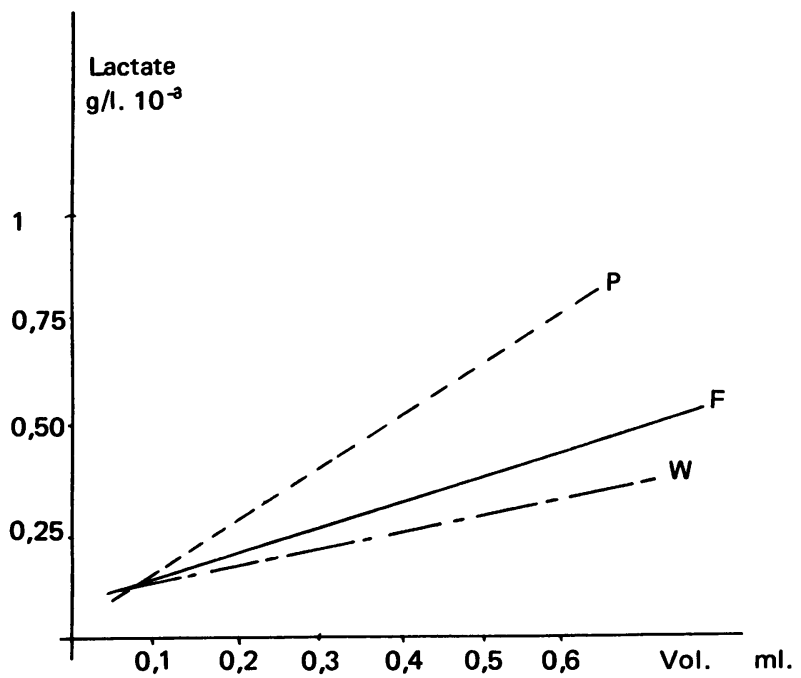

Fig. 1. The quantity of lactate is variable in terms of exercise.

The relation of pyruvate to lactate (Figure 2) shows the metabolic state of eccrine gland inactivity. In aerobic work, the pyruvate is used by the tricarboxylic circle

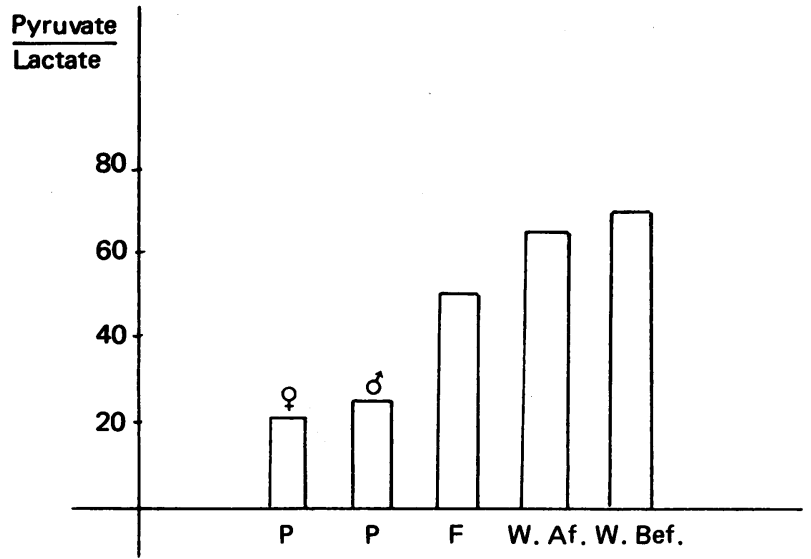

Fig. 2. Shows that the relation of pyruvate to lactate is different in terms of exercise.

The pyruvate/lactate value is higher during aerobic exercise than during anaerobic (football players, table tennis players).

and transformed into energy. During an anaerobic exercise, the LDH converts pyruvate into lactate with a loss of energy.

Trained athletes (walkers) have a high pyruvate/lactate ratio to begin with, and between the beginning and end of training this ratio decreases.

The latter investigation provides evidence that glucose in sweat reacts like pyruvic acid. Its concentration is higher during aerobic exercise (Figure 3).

\begin{tabular}{l|lll} 
& & & \\
Log. & $P_{W}=-1,9$ & $P_{f}=-1,7$ & $P_{p}=-0,98$ \\
Vol. & $R_{W}=0,68$ & $R_{f}=0,89$ & $R_{p}=0,6$ \\
& $\alpha<0,01$ & $\alpha<0,01$ & $\alpha<0,01$
\end{tabular}

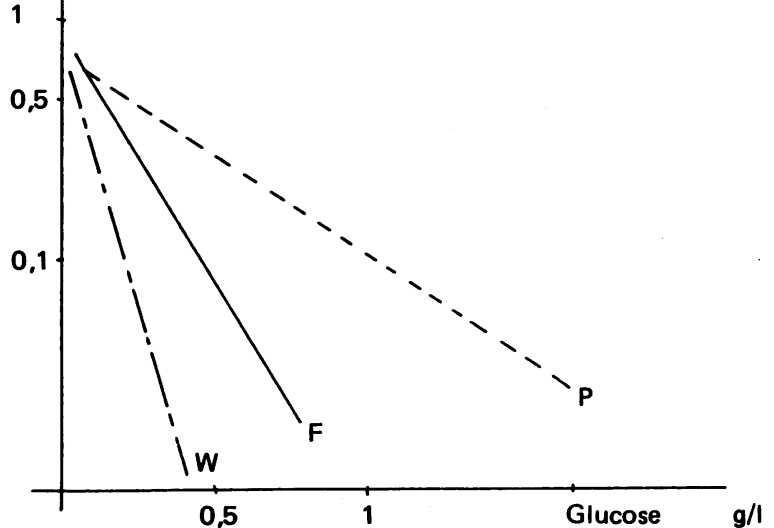

Fig. 3. The concentration of glucose is a log. function of volume and the declining slope is different in terms of each sport sampled. 
The sweat rate is the result of a stimulus which is proportional to metabolic rate and its composition (lactic and pyruvic acid, glucose) fluctuates in terms of training and type of exercise.

In connection with these determinations, we have titrated $\mathrm{Na}^{+}$and $\mathrm{K}^{+}$in sweat and in the urine. We tried to establish a relation between lactic acid and potassium excretion. Man can lose up to $5 \%$ of his body weight in sweat in a competition. $\mathrm{Na}^{+}$and $\mathrm{Cl}^{-}$are responsible for this secretion (heat acclimatization). But what are the effects of this mechanism during profuse sweating? If we study Aldosterone effects on sweat gland and kidney cells, we can observe:

a. In sweat $\mathrm{Na}^{+} / \mathrm{K}^{+}$increases during $3 \mathrm{~h}$. and then decreases.

b. In urine the relation $\mathrm{Na}^{+} / \mathrm{K}^{+}$reduces during $6 \mathrm{~h}$.

Our conclusion is that the secondary hyperaldosteronism (resulting from hypovolaemia and hyponatraemia) does not have a similar action on the eccrine sweat glands and the kidney cells. We can explain this phenomenon by the special metabolic state of the eccrine sweat glands. In reality the sweat gland must eliminate both water and $\mathrm{Na}^{+}$. The reabsorption of sodium by exchange with $\mathrm{K}^{+}$is thereby limited.

\section{CONCLUSIONS}

Our experiments support the contention that both potassium and lactic acid are secreted simultaneously. The secretion of lactate (anaerobic work) favours the excretion of $\mathrm{K}^{+}$ions.

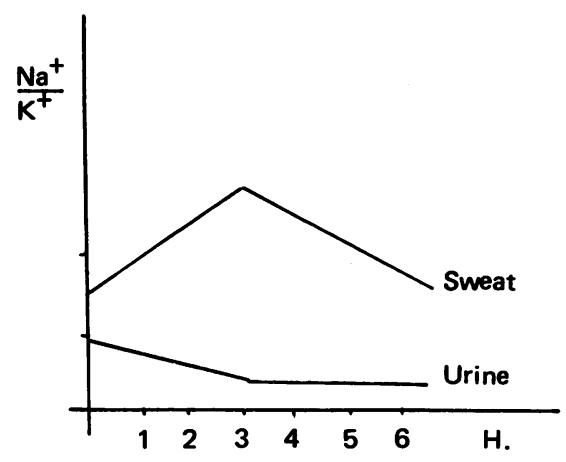

Fig. 4. Shows that $\mathrm{Na}^{+} / \mathrm{K}^{+}$increases during the first part of walking (3h.) and then decreases. In the urines $\mathrm{N}^{+} / K^{+}$decreases during $6 h$.

The composition of sweat during exercise is different from environmental hyperthermic sweat. These differences in ionic composition are supported by our findings;

a. That the lactate produced by anaerobic glycolysis is secreted into the intercellular canaliculi with $\mathrm{K}^{+}$, and its quantity depends upon training and on the state of both muscular and eccrine gland tissue.

b. That under aerobic condtions the pyruvate ando glucose are secreted in greater quantities than lactate is.? excreted.

c. That the $\mathrm{Na}^{+}$excreted is relatively independent of Aldosterone, and its regulation is essentially thermic.

\section{REFERENCES}

Adelman, S., Taylor C. R. and Heglund, C. H. 1975. "Sweating on paws and palms: what is its function?" Am.J.Physiol. 229: 1400-1402.

Allen, J. A. and Roddie, I. C. 1972. "The role of circulating catecholamines in sweat production in Man." J.Physiol.(Lond.) 227: 801-814.

Allen, J. A. and Roddie, I. C. 1974. "The effect of antidiuretic hormone on human sweating." J.Physiol. (Lond.) 236: 403-412.

Cage, G. W. and Dobson, R. L. 1965. "Sodium secretion and reabsorption in the human eccrine sweat gland." J.Clin.Invest. 44: 1270.

Collins, K. J. 1962. “Composition of palmar and forearm sweat." J.Appl.Physiol. 17: 99-102.

Collins, K. J. and Weiner, J. S. 1962. “Observation on arm bag suppression of sweating and its relationship to thermal sweat gland fatigue." J.Physiol. (Lond.) 161: 538.

Das, S. K., Chatterjee, S., Chatterjee, P. and Maitra, S. R. 1975. "Mechanism of sweat secretion during work with a new concept of thermoregulation." Ind.J.Physiol.and Allied Sci. 29: 1. 
Foster, K. G., Ginsburg, J. and Weiner, J. 1970. "Role of circulating catecholamines in human eccrine sweat gland control." Clin.Sci. 39: 823-832.

Robertshaw, D. 1975. "Catecholamines and control of sweat glands." Handbook of physiology Vol. VI Edited by American physiological society: 591-603.

Robertshaw, D. 1977. “Neuroendocrine control of sweat glands." J.Invest.Dermatol. 69: 121-129.

Sato, K. and Dobson, R. L. 1970. "The effect of intracutaneous aldosterone and hydrocortisone on human eccrine sweat gland function." J.Invest.Dermatol. 54: 450-462.

Uno, H. and Montagna, W. 1975. "Catecholamines containing nerve terminals of the eccrine sweat glands of macaques." Cell.Tissue Res. 158: 1-13.

\title{
OBITUARY
}

\author{
Dr. W. Lindsay Neustatter, BSc, MD, FRCP, FRCPsych.
}

Dr. Neustatter died on July 6 th after a long illness at the age of 74 . He was born in Munich, but came to Britain in early childhood. He gained a first class honours degree in 1924, then studied medicine at University College, London, obtaining the Conjoint Diploma in 1929 and MB,BS in 1931. His MD in psychological medicine was awarded in 1941, and he was elected FRCP in 1972, and in the same year a foundation FRCPsych. His main hospital appointment was consultant psychiatrist to the Royal Northern Hospital. He served in the RAMC during the Second World War, retiring with the rank of Lt. Col. He was a world authority on forensic psychiatry, and author of "The Mind of a Murderer" (1956) and many other works.

Throughout his life Dr. Neustatter was a keen sportsman, outstanding in fives and tennis, a keen cricketer, and in later life an enthusiastic follower of these sports. The effects of cerebral trauma combined his professional and sports interests, and he was one of the speakers in the BASM's two-day symposium on medical aspects of boxing, held in 1963. At this time, he joined the BASM and continued his membership after retirement until 1977. His death will be a great loss to psychiatry and to sport.

H. E. Robson 